\title{
Study of breastfeeding practices and problems among postnatal mothers: a hospital based study
}

\author{
Pooja J. Mise ${ }^{1 *}$, Aditya J. Mise², Sangamesh J. Mise³, Margol Siddappa ${ }^{4}$
}

\begin{abstract}
${ }^{1}$ Department of Obstetrics and Gynecology, Gulbarga Institute of Medical Sciences, Kalaburagi, Karnataka, India ${ }^{2}$ Department of PSM, Karnataka Institute of Medical Sciences, Hubli, Karnataka, India ${ }^{3}$ Department of General Surgery, Mahadevappa Rampure Medical College, Kalaburgi, Karnataka, India ${ }^{4}$ Department of Medicine, Gulbarga Heart Foundation, Kalaburgi, Karnataka, India
\end{abstract}

Received: 11 July 2017

Accepted: 15 July 2017

\section{*Correspondence:}

Dr. Pooja J. Mise,

E-mail: poojasiddum@gmail.com

Copyright: ( ) the author(s), publisher and licensee Medip Academy. This is an open-access article distributed under the terms of the Creative Commons Attribution Non-Commercial License, which permits unrestricted non-commercial use, distribution, and reproduction in any medium, provided the original work is properly cited.

\begin{abstract}
Background: Breastfeeding has many health and developmental advantages for infant and mothers. Breastfeeding remains the simplest, healthiest and least expensive feeding method that fulfils the infant's needs.

Methods: 112 mothers having infants of age group less than 1 year were included in the study. Self-administered questionnaire was used to collect information on breastfeeding practices in the initial six months of birth of the child. Study population were postnatal mothers in KIMS Hubli, Hospital IPD and OPD.

Results: 112 lactating mothers were included in the study. Majority of subjects $86(76.7 \%)$ were in the age group 21 30 years. About 43 (38.4\%) lactating mother initiated breast feeding practices within 1 hour after the delivery. $63.4 \%$ of the infants received exclusive breast feeding. Lactation failure $40 \%$ and unsatisfactory growth of baby $50 \%$ were the main reasons for early weaning. Most common cause of delay in initiation in breast were caesarian section and delivery complication (53.12\% and $21.88 \%$ respectively) Only 27 (24.1\%) babies were given pre-lacteal feed.

Conclusions: There is a need of giving information regarding breast feeding during antenatal visits to inform the mothers regarding proven facts of advantages of exclusive breastfeeding, as undesirable cultural practices such as giving pre-lacteals, late initiation of breast feeding are still prevalent among the community and these should be discouraged. For successful feeding, mothers need active support, care and privacy during pregnancy and following birth, not only of their families and communities but also of the entire health system.
\end{abstract}

Keywords: Colostrum, Exclusive breastfeeding, Postnatal, Pre-lacteal feeds, Weaning

\section{INTRODUCTION}

Breast feeding is the first fundamental right of the child. It provides a unique biological and emotional basis for the health development of the children.

It offers infants and young children complete nutrition, early protection against illness and promote growth and development of the baby. Early initiation of breast feeding lowers the mother's risk of postpartum haemorrhage and anaemia.
The beneficial effect of breastfeeding depends on breastfeeding initiation, its duration, and age at which the breast-fed child is weaned. Breastfeeding practices vary among different regions and communities. In India breastfeeding practices are influenced by rural and urban residence, cultural, socio-economic factors, psychological status, religious value and literacy especially low level of mother's education, mother's employment. As per WHO's recommendation breast milk alone is sufficient to meet the infant's nutritional requirements for the first 6 months of life. The world health organization 
recommends that breastfeeding be initiated within $1 \mathrm{hr}$ of birth. Early initiation of breastfeeding provides benefits for both mother and the baby.,2 The baby friendly hospital initiative (BFHI) was designed to promote early initiation of breastfeeding preferably immediately after the birth.

Exclusive breastfeeding for the first 6 months of life and timely introduction of weaning food is important for laying down proper foundations of growth in later childhood. $^{3,4}$

Pregnancy and post-partum period is time of great transition in women's life. It is complex to understand relationship between post-partum care breastfeeding and infant wellbeing.

Health outcomes in developed countries differ substantially for mothers and infants who formula feed compared with those who breastfeed. For infants, not being breastfed is associated with an increased incidence of infectious morbidity, as well as elevated risks of childhood obesity, type 1 and type 2 diabetes, leukemia, and sudden infant death syndrome. For mothers, failure to breastfeed is associated with an increased incidence of premenopausal breast cancer, ovarian cancer, retained gestational weight gain, type 2 diabetes, myocardial infarction, and the metabolic syndrome..$^{5,6}$ Obstetricians are uniquely positioned to counsel mothers about the health impact of breastfeeding and to ensure that mothers and infants receive appropriate, evidence-based care, starting at birth.

By assessing the knowledge, attitude and practices of lactating mothers regarding their child's feeding, an overview can be obtained about the areas which need modifications and hence specific intervention strategies can be made to correct the same.,

\section{METHODS}

Study population: Study population were postnatal mothers attending OPD and IPD KIMS Hubli Hospital. Sample size: Sample of 112. Sampling method: Convenient sampling. Study area: KIMS Hubli Karnataka. Study duration: Study was conducted for duration of 1 month.

\section{Inclusion criteria}

Postnatal mothers of sex and age group less than 1 year were included in the study.

\section{Exclusion criteria}

Infants who had chronic illness, mental disorders, and those mothers who were reluctant to give consent for the interview were excluded.
Method used: Semi-structured questionnaire consisting of 32 questions was prepared. Information regarding exclusive breastfeeding early initiation of breastfeeding, prevalent methods of infants feeding practices were studied.

\section{Statistical analysis}

The data was analysed using SPSS 17.0 to derive percentages, proportions and chi-square tests.

\section{RESULTS}

The present study carried out in KIMS Hubli Hospital included a total 112 lactating mothers having children less than 1 year. Majority of the mothers (76.7\%) studied belong to age group 21-30years.

Table 1: Distribution of mother age.

\begin{tabular}{|lll|}
\hline Age of mothers (years) & Number & $\%$ \\
\hline $15-20$ & 22 & 19.6 \\
\hline $21-30$ & 86 & 76.7 \\
\hline $31-40$ & 4 & 3.7 \\
\hline Total & 112 & 100 \\
\hline
\end{tabular}

Among them majority of the study population is literate up to secondary schooling followed with primary schooling and graduates. $90.2 \%$ of study population is graduated predominantly secondary schooling. $9.8 \%$ of lactating mothers were illiterate. Only $8.9 \%$ of the cases belong to poor and BPL category. Moreover, $76 \%$ of the mother belong to high and upper middle group of socioeconomic status. $60.7 \%$ of the study people come from urban areas and only $39.3 \%$ come from rural areas.

Table 2: Distribution of cases according to exclusive breastfeeding.

\begin{tabular}{|lll|}
\hline Exclusive breast feeding & Frequency & $\%$ \\
\hline No & 41 & 36.6 \\
\hline Yes & 71 & 63.4 \\
\hline Total & 112 & 100.0 \\
\hline
\end{tabular}

$63.4 \%$ of infants received exclusive breast-feeding way about the national average of $46.3 \% .^{9}$

Table 3: Distribution of cases according to type of feeding.

\begin{tabular}{|lll|}
\hline Type of feeding & Frequency & $\%$ \\
\hline On demand & 68 & 60.7 \\
\hline Scheduled & 44 & 39.3 \\
\hline Total & 112 & 100.0 \\
\hline
\end{tabular}

$60.7 \%$ of the infants received breast milk on demand basis and $39.3 \%$ thought that breastfeeding should be given at scheduled time. 
Table 4: Distribution of cases on opinion on time of exclusive breastfeeding.

\begin{tabular}{|c|c|c|}
\hline Time (in months) & Frequency & $\%$ \\
\hline 3 & 3 & 2.7 \\
\hline 4 & 4 & 3.6 \\
\hline 5 & 7 & 6.3 \\
\hline 6 & 83 & 74.1 \\
\hline$>6$ & 15 & 13.3 \\
\hline Total & 112 & 100.0 \\
\hline
\end{tabular}

Majority $(74.1 \%)$ cases have an opinion that exclusive breastfeeding should be continued up to 6 months of age.

Table 5: Distribution of cases on time of initiation of breastfeeding.

\begin{tabular}{|c|c|c|}
\hline Time (in hours) & Frequency & $\%$ \\
\hline 1 & 43 & 38.4 \\
\hline 4 & 34 & 30.4 \\
\hline 24 & 13 & 11.6 \\
\hline 48 & 12 & 10.7 \\
\hline 72 & 5 & 4.5 \\
\hline$>72$ & 5 & 4.5 \\
\hline Total & 112 & 100.0 \\
\hline
\end{tabular}

$38 \%$ of the cases initiated breastfeeding within 1 hour of delivery, $30.4 \%$ after 4 hours and $11.6 \%$ on the $1^{\text {st }}$ day.

Table 6: Distribution showing whether mothers fed colostrum or not.

\begin{tabular}{|c|c|c|}
\hline Colostrum feeding & Frequency & $\%$ \\
\hline No & 13 & 11.6 \\
\hline Yes & 99 & 88.4 \\
\hline Total & 112 & 100.0 \\
\hline
\end{tabular}

Majority of mothers (88.4\%) fed their children with colostrum.

Table 7: Distribution of cases based on type of prelacteal feeds.

\begin{tabular}{|lll|}
\hline Type & Frequency & $\%$ \\
\hline No prelacteal feeds & 85 & 75.9 \\
\hline Cow milk & 5 & 4.5 \\
\hline Honey & 16 & 14.3 \\
\hline Sugar water & 2 & 1.8 \\
\hline Water & 4 & 3.6 \\
\hline
\end{tabular}

It was observed that $75.9 \%$ of the lactating mothers did not believe in giving pre-lacteal feeds. $14.3 \%$ mothers used honey as pre-lacteal feeds followed by cow's milk. The percentage of mothers from rural area who gave prelacteal feed was relatively more than urban counterparts.

Majority $(64.3 \%)$ of the cases started weaning practices at 6 months and $24.1 \%$ at 1 years of age. There is no much effect of socio-economic status on weaning practices.

Table 8: Distribution of cases showing time of initiation of weaning.

\begin{tabular}{|lll|}
\hline Time (in months) & Frequency & $\%$ \\
\hline$<5$ & 3 & 2.7 \\
\hline 5 & 10 & 8.9 \\
\hline 6 & 72 & 64.3 \\
\hline 12 & 27 & 24.1 \\
\hline Total & 112 & 100.0 \\
\hline
\end{tabular}

Lactation failure and unsatisfactory growth of baby were the main reasons for early weaning.

Table 9: Reasons for early weaning.

\begin{tabular}{|lll|}
\hline Reason & Frequency & $\%$ \\
\hline Lactation failure & 4 & 40 \\
\hline Maternal illness & 1 & 10 \\
\hline Failure to thrive & 5 & 50 \\
\hline Total & 10 & 100 \\
\hline
\end{tabular}

\section{DISCUSSION}

According to our study majority $(68.4 \%)$ of mothers put their babies to breast within $1 \mathrm{hr}$ to $4 \mathrm{hrs}$. Literacy status does not have much effect on the time of initiation of breastfeeding. The effect of socio-economic status on initiation of breastfeeding could not be evidenced significant $(\Phi 2=13.793, \mathrm{DF}=20, \mathrm{p}>0.05)$.

In a study conducted in Aligarh, by MA Ansari et al. breastfeeding was started between half to 5 hr by majority of the mothers. In a study by Alok Kumar et al only less than half of total interviewed mothers were able to initiate breastfeeding within $24 \mathrm{hrs}$ of birth.

The study conducted in Aligarh, by Ansari MA et al. reveals that literacy status had little impact on initiation of breastfeeding. ${ }^{10}$ However, an early initiation was observed in comparatively more educated mother. Alok Kumar et al in their study reiterated the same findings. ${ }^{11}$

In a study conducted by Faizabad, by Tiwari $\mathrm{V}$ at al. the effect of socio-economic status on initiation of breastfeeding could not be evidenced significant $(\Phi 2=1.614, \mathrm{DF}=2, \mathrm{p}<0.01) .{ }^{12}$

In our study, an overwhelming majority $(88,4 \%)$ of mothers fed their children with colostrum, more over a cent percent of graduate mothers fed their children with colostrum. We found that honey $(14.3 \%)$ was the most pre-lacteal feed, followed by cow milk (4.5\%).

In a study conducted in Faizabad, by Tiwari $\mathrm{V}$ et al. majority of mothers did not discard colostrum and they fed it to their children. Also, the study suggested that the 
enhancement in maternal literacy may be proved helpful to initiate breastfeeding as earliest as possible, and practice of colostrum feeding by them. ${ }^{12}$

Mandal PK et al. in their study also found that $71.7 \%$ infants were given pre-lacteal feeds. Among pre-lacteal feeds honey $(25 \%)$ was commonest followed by other substances like water $(18 \%)$ etc. ${ }^{13}$

In our study, the rates of exclusive breast feeding were found at $88.4 \%$. According to our study, $26.6 \%$ of mothers resorted to top feeds for their children along with breastfeeding. In a study conducted in rural Karnataka, by H.B. Mallikarjun et al. $25.6 \%$ of mothers had resorted to top feeds for 'better growth of the child' during 5-6 months of age. ${ }^{14}$

In a study by Shiva $\mathrm{F}$ et al the percentage of infants being exclusively breastfed fell from $90 \%$ at 1 month, to around $83 \%$ at 6 months. According to NFHS-3exclusive breastfeeding in children under 6 months is only $46.4 \% .^{15}$ According to our study, in majority of infants that we studied, weaning was started at 6 months $(64.3 \%)$. in our study, only $8.9 \%$ of the mothers started weaning their children early, out of whom 5 mothers (50\%) cited unsatisfactory growth of the child, followed by lactation failure (40\%) as the reason for early weaning.

In a study by Shiva $\mathrm{F}$ et al, the majority of infants studied, the weaning process was started around 3 months of age. ${ }^{15}$ In a study in rural West Bengal by Mandal PK et al. It was revealed that 'lactation failure' was the commonest $(71.6 \%)$ reason for complimentary feeding as started by the mothers followed by unsatisfactory growth of the child 'Mothers illness' etc.

\section{CONCLUSION}

Breastfeeding is observed to be a universal practice in the study area and accepted to be healthiest food for infants. The effect of literacy status of mothers on breastfeeding practices is not very evident. Healthy breastfeeding practices has significant effect on mothers and infants.

Funding: No funding sources Conflict of interest: None declared

Ethical approval: The study was approved by the Institutional Ethics Committee

\section{REFERENCES}

1. WHO. Breast feeding; 2009 Available at http://www.who.int/entity/child_adolescent_health/to pics/prevention_care/child/nutrition/breastfeeding/en
2. World Health Organization, Regional Office for South-East Asia. The Optimal Duration of Exclusive Breastfeeding: A Systematic Review. World Health Organization, Geneva: 2002. Available at: http://www.who.int/nutrition/publications/optimal duration_of_ex c_bfeeding_review_eng.pdf.

3. Yilmaz E, Ocal FD, Yilmaz ZV, Ceyhan M. Early initiation and exclusive breastfeeding: Factors influencing the attitudes of mothers who gave birth in a baby friendly hospital. Turkish J Obstet Gynaecol. 2017;14:1-9.

4. Dadhich JP, RK Agarwal. Mainstreaming early and exclusive breastfeeding for improving child survival. Indian Paediatrics. 2009;46:11-7.

5. CheZem J, Friesen C, and Boettcher J. Breastfeeding knowledge, breastfeeding confidence and infant feeding plans: Effects on actual feeding practice. J Obstetr Gynecol Neonat Nurs. 2003;32(1):42-7.

6. Dutton, M. A. A breastfeeding protocol. J Ostetrics Gynecol Neonat Nurs. 1979;8(3):151-5.

7. Oommen A, Vatsa M, Paul VK, Agarwal R. Breastfeeding practices of urban and rural mothers. Ind Paediatr. 2009;46:891-4.

8. Brodribb W. Barriers to translating evidence-based breastfeeding information into practice. Acta Paediatrica. 2011;100(4):486-90.

9. Govt. of India. National family health survey III (2005-2006). In: IIPS, eds. IIPS Survey. Mumbai: Ministry of Health and Family Welfare; 2007:1-24.

10. Ansari MA, Khan Z, Khan IM. Hospital based study on breastfeeding practices in Aligarh. Ind J Prevent Soc Medic. 2007;38(1-2):69-74.

11. Kumar A, Verma P, Singh VS, Kansal S. Breastfeeding practices in rural eastern uttar pradesh: a descriptive cross-sectional study. Indian J Prev Soc Med. 2011;42(2):193-8.

12. Tiwari V, Singh A. Knowledge attitude and practice of mothers regarding breast feeding in an urban area of Faizabad district (UP). Ind J Prevent Soc Medic. 2007;38(1-2):18-22.

13. Mandal PK, Sardar JC, Chatterjee C, Lahiri SK, Ghosh P. A study of breast feeding practices among infants in a rural area of West Bengal. Ind J Prevent Soc Medic. 2007;38(1-2):28-31.

14. Mallikarjun HB, Banapurmath CR, Shobha B, Kesari $\mathrm{N}$. Breastfeeding problems in first 6 months of life in rural Karnataka. Indian Pediatr. 2002;39:861-4.

15. Shiva F, Nasiri M. A study of feeding patterns in young infants. J Trop Pediatr. 2003;49(2):89-92.

Cite this article as: Mise PJ, Mise AJ, Mise SJ, Siddappa M. Study of breastfeeding practices and problems among postnatal mothers: a hospital based study. Int J Reprod Contracept Obstet Gynecol 2017;6:3343-6. 